\title{
Obsesif Kompulsif Bozukluk Hastalarında Klinik Değerlendirme ölçekleri ile EEG Senkronizasyonu Arasındaki Korelasyon
}

\author{
Mehmet Akif ÖZÇOBAN ${ }^{* 1}$, Aydın AKAN², Oğuz TAN ${ }^{3}$, Serap AYDIN ${ }^{4}$ \\ ${ }^{1}$ İstanbul Üniversitesi, Fen Bilimleri Enstitüsü, Biyomedikal Mühendisliği ABD, İstanbul \\ 2̇̇zmir Katip Çelebi Üniversitesi, Mühendislik-Mimarlık Fakültesi, Biyomedikal Mühendisliği Bölümü, İstanbul \\ 3Ǘsküdar Üniversitesi, İnsan ve Toplum Bilimleri Fakültesi, Psikoloji Bölümü, İstanbul \\ ${ }^{4}$ Beykent Üniversitesi, Mühendislik-Mimarlık Fakültesi, Biyomedikal Mühendisliği Bölümü, İstanbul
}

(Alınış / Received: 23.12.2016, Kabul / Accepted: 27.07.2017, Online Yayınlanma / Published Online: 09.10.2017)

\author{
Anahtar Kelimeler \\ Obsesif kompulsif \\ bozukluklar, \\ EEG, \\ Senkronizasyon
}

\begin{abstract}
Özet: Obsesif Kompulsif Bozuklular (OKB) başka psikiyatrik belirtilerin de eşlik edebildiği nöropsikiyatrik bir hastalıktır. OKB için başlıca klinik değerlendirme kriteri, Yale-Brown Obsesyon Kompulsiyon Ölçeği (YBOKÖ) olsa da bunun yanı sıra, Hamilton Depresyon Değerlendirme Ölçeği (HDDÖ), Beck Anksiyete Ölçeği (BAÖ)de kullanılmaktadır. Bu çalışma da OKB değerlendirme ölçekleri ile EEG senkronizasyonu arasında ki ilișki incelenmiștir. EEG senkronizasyonunu belirlemek için Global Alan Senkronizasyonu yöntemi ile hesaplanan GAS indisi kullanılmıștır. 30 adet OKB hastasına ait GAS indisleri ile bu hastalara ait OKB Klinik Değerlendirme Ölçekleri, arasındaki ilişki Spearman-rho korelasyon yöntemi ile incelenmiștir. Analiz sonuçlarına göre alfa 1 frekans bandında ki GAS değerleri ile BAÖ arasında negatif ilişki bulunurken, teta, alfa 1 ve alfa 2 bantlarındaki GAS değerleri ile HDDÖ arasında, negatif ilişki tespit edilmiştir. $\mathrm{Bu}$ sonuçlar, OKB hastalarında anksiyete ve depresyon belirtilerinin senkronizasyon bozukluğuna bağlı olarak fonksiyonel bağlılıkta azalışa neden olduğunu göstermektedir. OKB'ye eşlik eden anksiyete ve depresyon şiddetindeki artışın, bilişsel işlem düzeyinde düşüşe neden olduğu görülmüştür.
\end{abstract}

\section{Correlation Between Clinical Rating Scales of Obsessive Compulsive Disorders Patients and EEG Synchronization}

\section{Keywords}

Obsessive compulsive

disorders,

EEG,

Synchronization

\begin{abstract}
Obsessive compulsive disorder (OCD) is a neuropsychiatric disease may be comorbid with symptoms of other psychiatric disease. Although the main clinical rating criteria of OCD is Yale Brown Obsession Compulsion Score (YBOCS), Hamilton Deppression Rating Score (HDRS-17) and Beck Anxiety Inventory (BAI) are also used. In this study, the correlation between EEG synchronization and rating scales of OCD was examined. In order to determining Synchronization of EEG data, Global Field Synchronization (GFS) Indice was producted by GFS method. Correlation between GFS indice of EEG data were recorded from 30 OCD and Clinical Raitng Scales of the patients was examined with Spearman-rho correlation method. In according to analysis results; GFS values in the alfa 1 band were negatively correlated with the BAI and the values in theta, alfa 1 and alfa 2 was negatively correlated with HDRS-17. This results showed that symptoms of anxiety and depression in OCD, causes functional diconnectivity depends on desynchronization. High severity of anxiety and depression comorbid with OCD, causes cognitive decline
\end{abstract}

\section{Giris}

Obsesyon; insan zihnine, zorla giren ve yanlış olduğunu bildiği halde inanmak zorunda hissettiren rahatsızlı verici imge ve düşüncelerdir. Kompulsiyon ise obsesyonların tetiklediği ve güdülediği, kişide özgüven azalmasına neden olan, bıktırıcı derecede tekrarlayan ve yapılmak zorunda hissedilen davranışlardır. En genel obsesyonlar; bulaşıcı hastalık korkusu, aşırı şüphecilik ve dini ritüellerde hata yapma endişeleridir. Yaygın kompulsiyon belirtileri ise; sürekli kontrol etme dürtüsü, gereğinden fazla sayıda tekrarlayan el yıkama ve belirli cümleleri sesli olarak söyleme gibi 
davranışlardır. Obsesif Kompulsif Bozukluklar (OKB) ise klinik semptomlarında obsesyon veya kompulsiyonların, kişiye rahatsızlık verici derecede görüldüğü nöropsikiyatrik bir hastalıktır [1]. OKB; nöropsikiyatrik bir hastalık olduğu için; nedenleri , teşhis ve tedavi yöntemlerinin araştırılmasında sıklıkla EEG tekniğine başvurulmaktadır. OKB tedavisi için yapılan bir araştırmada derin beyin uyartımı yöntemine yardımcı olarak kullanılan EEG [2], hastalığın beyinde ki bölgesel incelemesinde topografik analiz için [3], EEG işaret gücü ile semptom parametrelerinin ilişkilerinin incelenmesinde [4], koherans ve kaynak analizi çalışmalarında [5], OKB'nin nöroanatomik nedenlerinin araştırılmasında [6] kullanılmıştır.

Önceki çalışmalardan, EEG senkronizasyonunun beyin ağları arasındaki bağlılık gücü başta olmak üzere nörofizyolojik birçok bilgi verdiği bilinmektedir. EEG datasına ait senkronizasyon kuvveti hesaplamasında literatürde bir çok yöntem kullanılmıştır: Çoklu zaman serilerine ait faz senkronizasyonu [7], S tahmin edici [8], Global Senkronizasyon İndisi (GSİ) [9, 10], Global Kuplaj İndisi (GKİ) [11].

Faz tabanlı senkronizasyon hesaplamalarında yeni bir yöntem olan Global Alan Senkronizasyon (GAS) yöntemi, bütün beyin bölgelerindeki fonksiyonel senkronizasyonu hesaplayabilmektedir. GFS, farklı beyin işlemleri arasındaki bağlantısallık gücünü, her frekans bandı için ayrı ayrı gösterebilmektedir. Birçok nöropsikiyatrik hastalığın (şizofreni [12], Alzheimer hastalığı [13]) fonksiyonel bağlılık gücünü zayıflattığı, önceki çalışmalarda ifade edilmiştir. Bu çalışma da ise OKB hastalığının senkronizasyon ölçüm yöntemlerinden GAS yöntemi kullanılarak fonksiyonel bağlılı̆̆ı nasıl etkilediği ve GAS değerleri ile klinik araştırılmaktadır. GAS değerleri ile klinik değerlendirme ölçekleri arasındaki ilişki incelenmektedir.

\subsection{OKB}

Hastaya birincil tanı olarak OKB teşhisinin yapıldığı durumlarda, anksiyete ve depresyon skorları çalışma dışında bırakılmamaktadır. $\mathrm{Bu}$ nedenle hastalığın klinik karakteristikleri ve şiddet parametreleri tanımlanırken Yale-Brown Obsesyon Kompulsiyon Ölçeğinin (YBOKÖ) yanı sıra, Hamilton Depresyon Değerlendirme Ölçeği (HDDÖ), Beck Anksiyete Ölçeği (BAÖ) de kullanılmaktadır. [14]

Geçmişte, yapılan benzer bir çalışmada: her bir frekans bandına ait EEG işaret gücü ile YBOCS ölçeğinin alt skorları (obsesyon ve kompulsiyon) karşılaştırılmış ve güç değerleri ile obsesyon arasında pozitif ilişki bulunurken, kompulsiyon ile negatif ilişki bulunmuştur, [4] başka çalışmalarda ise kaynak lokalizasyonu ve koherans belirlenmesinde, [5] kompleksite analizinde [15] ve faz senkronizasyonu tabanlı çalışmalarda, ölçüm sonuçları ile klinik değerlendirme ölçekleri arasındaki ilişki incelenmiştir [16]. Bu çalışma da ise OKB hastalarına ait EEG datalarının Global Alan Senkronizasyonu yöntemi ile ölçülen senkronizasyon değerleri ile aynı hastaların, hastalık şiddeti ve hastalığa eşlik eden semptomlara ait klinik değerleri arasındaki ilişki Spearman-rho korelasyon analizi yöntemi ile araştırılmıștır.

\section{Materyal ve Metot}

\section{1. Çalıșmada kullanılan EEG dataları}

Çalışmada kullanılan EEG dataları, Üsküdar Üniversitesi Nöropsikiyatri Sağlık Uygulama ve Araştırma Merkezi tedavi görmek amacıyla başvuran OKB hastalarından kaydedilmiştir. Veriler; sağ elini kullanan, sigara içmeyen ve henüz herhangi bir tedavi görmemiş, kafa travması hikayesi olmayan, $30 \mathrm{OKB}$ hastasından alınmıştır. EEG verilerinin bilgisayar ortamında analiz edilmesi için Üsküdar Üniversitesi Klinik Araștırmalar Etik Kurulundan onay alınmıștır. Kayıtlar, 19 elektrotlu (kanal sayısı) Neuroscan Synamps II (Neuroscan Products Compumedics, USA) cihazı ile alınmıştır. Cihazın elektrotları başlık üzerinde uluslararası 10-20 elektrot sistemine göre yerleştirilmiştir. Örnekleme frekansı $250 \mathrm{~Hz}$ ve 16 bitliktir analog-dijital dönüştürücü kullanılmıştır. Elektrotlar $\mathrm{Ag} / \mathrm{AgCl}$ den imal edilmiş olup empedans değerleri $5 \mathrm{k} \Omega$ 'dan daha küçüktür. Kayıt sırasında, göz kapaklarının hareketlerinden dolayı oluşan Elektrookulografik (EOG) işaretler ve şebeke geriliminden kaynaklanan gürültü işaretleri filtre yardımı ile elimine edilmiştir. Kayıt esnasında gönüllülerin gözleri kapalı ses yalıtımlı bir odada, herhangi bir uyaran olmaksızın rahat bir koltukta oturur vaziyettedir. Zihinsel Bozuklukların Tanısal ve İstatistiksel El Kitabına (DSM-V) [17] göre OKB'nin nöropsikiyatrik teşhisinde kullanılan klinik değerlendirme ölçekleri: Yale-Brown Obsesyon Kompulsiyon Ölçeği (YBOKÖ) [18], Hamilton Depresyon Değerlendirme Ölçeği (HDDÖ) [19], Beck Anksiyete Ölçeğidir (BAÖ) [20].

\subsection{Yöntem}

EEG kayıtları 3 dakika boyunca sürekli olarak alınmıștır. Daha sonra analiz edilmek için 2 saniyelik bölütlere ayrılmıştır. Buna göre GAS analizler bir bölüt için ayrı ayrı hesaplandıktan sonra ortalama değer, incelenen frekans bölgesi için senkronizasyon gücünü vermektedir. Hesaplamalar için, frekans bantları : Delta (1.5-6.0 Hz), Teta (6.5-8.0 Hz), Alfa1 (8.5-10.0 Hz), Alfa2 (10.5-12.0 Hz), Beta1(12.5-18.0 $\mathrm{Hz})$, Beta2 (18.5-21.0 Hz) ve Gama (21.5-30.0) Hz kabul edilmiştir [21].

\subsection{Global alan senkronizasyonu}

Temelde GAS yöntemi bir çeşit faz belirleme işlemidir. GAS yönteminin bir EEG datasına uygulanmasının sonucunda senkronizasyon gücünü 
belirleyen bir indis bulunmaktadır. GAS indisi her frekans noktası için ayrı ayrı hesaplandıktan sonra ortalaması alınarak, EEG senkronizasyonu belirlenebilmektedir. GAS yöntemi aşağıda ki adımlar takip edilerek hesaplanabilecektir.

EEG dataları 2saniyelik zaman pencerelerine bölünür. Her bir pencereye Hılı Fourier Dönüşümü (HFD) yöntemi uygulanarak, frekans domenine dönüştürülmesinden sonra, elde edilen komplex değerlerin reel ve imajiner kısımları iki boyutlu kartezyen sisteme yerleștirilmektedir. Bu sistemin polar notasyon ile gösterildiğinde, her bir elektroda ait değerler bir vektör ile temsil edilir. Bu vektörlerin dağılım şekli, elektrotlardan alınan işaretlerin ortak fazlılığı ile ilgili bilgi vereceği için, elektrotları temsil eden noktalara Temel Bileşenler Analizi yöntemi (TBA) uygulanmaktadır. Bu işlemin sonucunda her frekans için iki özdeğer elde edilmektedir [13].

$$
G A S(f)=\frac{\left|\ddot{\mathrm{o}}_{(f) 1}-\ddot{\mathrm{O}}_{(f) 2}\right|}{\ddot{\mathrm{O}}_{(f) 1}+\ddot{\mathrm{O}}_{(f) 2}}
$$

Elde edilen özdeğerler Denklem 1'de [12] hesaplanarak söz konusu frekans bandı için GAS indisi hesaplanmış olmaktadır.

\section{Bulgular}

$\mathrm{Bu}$ çalışmada 30 OKB hastasına ait senkronizasyon parametresi GAS yöntemi ile hesaplanmıştır. Üsküdar Üniversitesi Nöropsikiyatri Sağlık Uygulama ve Araştırma Merkezinde çalışan uzmanlar tarafindan tetkik edilerek saptanan OKB hastalık şiddetini gösteren klinik değerler (YBOCS, HDRS-17, BAI) ile GAS indisi arasında ki ilişki, Spearman-rho korelasyon analizi (SKA) yöntemi ile araştırılmıştır. Analiz sonuçları Tablo 1' de gösterilmektedir.

Tablo 1. GAS değerleri ile OKB klinik karakteristikleri arasındaki ilișki

\begin{tabular}{lcccccc}
\hline & \multicolumn{2}{c}{ YBOKÖ } & \multicolumn{2}{c}{ BAÖ } & \multicolumn{2}{c}{ HDDÖ } \\
r & $\mathrm{p}$ & $\mathrm{r}$ & $\mathrm{p}$ & $\mathrm{r}$ & $\mathrm{p}$ \\
\hline Delta Bandında ki GAS Değeri & -0.430 & 0.790 & 0.279 & 0.070 & 0.016 & 0.927 \\
Telta Bandında ki GAS Değeri & -0.169 & 0.269 & -0.180 & 0.260 & -0.356 & $0.023^{*}$ \\
Alfa 1 Bandında ki GAS Değeri -0.189 & 0.219 & -0.260 & 0.093 & -0.368 & $0.011^{*}$ \\
Alfa 2 Bandında ki GAS Değeri -0.090 & 0.574 & -0.380 & $0.016^{*}$ & -0.370 & $0.018^{*}$ \\
Beta 1 Bandında ki GAS Değeri & 0.089 & 0.569 & 0.117 & 0.460 & 0.180 & 0.265 \\
Beta 2 Bandında ki GAS Değeri & 0.055 & 0.726 & 0.475 & 0.220 & 0.546 & 0.110 \\
Gama Bandında ki GAS Değeri & 0.165 & 0.300 & 0.370 & 0.118 & -0.505 & 0.120 \\
\hline * Anlamlılık derecesi 0.05'in altında olan değerlerdir. & & & \\
r: Spearman korelasyon katsayısı, p: istatistiksel anlamlılık derecesi &
\end{tabular}

Analiz sonuçlarına göre, OKB hastalığı ile birlikte görülen Beck Anksiyete Ölçeği (BAÖ) değerleri ile GAS parametresi (alfa 2 bandında) arasında negatif bir ilişki bulunmaktadır. Hamilton Depresyon Değerlendirme Ölçeği (HDDÖ) ile teta, alfa 1 ve alfa 2 bantlarında GAS parametresi arasında istatistiksel olarak anlamlı $(\mathrm{p}<0.05)$ negatif ilişki bulunmuştur. Yale Brown Obsesyon Kompulsiyon Ölçeği (YBOKÖ) ile senkronizasyon indisi arasında anlamlı bir ilişki saptanmamıştır.

\section{Tartışma ve Sonuç}

Önceki çalışmalarda OKB hastalarına ait GAS değerleri, sağlıklı gruba göre istatistiksel olarak anlamlı şekilde düşük bulunmuştur, [16] anksiyete ve depresyon ile ilgili bir araştırmada ise anksiyete şiddeti artışının alfa bandında senkronizasyon kaybına neden olduğu belirtilmiştir ve senkronizasyon bozukluğunun bilişsel işlemlerde performans düşüklüğüne neden olduğu belirtilmiştir [22]. OKB hastaları ile yapılan başka bir araștırmada, OKB'nin bilinç üzerinde olumsuz etkileri olduğu saptanmıştır [14]. Bu çalışmada ise OKB'ye eşlik eden anksiyete ve depresyon şiddetleri arttıkça, istatistiksel olarak anlamlı şekilde GAS değerinin düştüğü gözlenmiștir. Çalışmada ulaşılan bulgular daha önce yapılan çalışmaları doğrular nitelikte sonuçlar vermiştir. Bilgimize göre senkronizasyon ile bilişsel işlemleri birlikte araştıran ilk çalışma olduğu için, önemli bir boşluğu doldurmaktadır.

\section{Teşekkür}

Bern Psikiyatri Üniversitesi Psikiyatrik Nörofizyoloji bölümü Öğretim Üyesi Prof. Dr. Thomas Koenig'e ve İstanbul Gedik Üniversitesi Tıbbi Görüntüleme Teknikleri Programından Öğr. Gör. Sebahattin Babur'a önerileri ve yorumları ile sağladıkları katkılardan dolayı teşekkür ederiz.

\section{Kaynakça}

[1] Saxena, S., and Rauch, S.L.: 'Functional neuroimaging and the neuroanatomy of obsessive-compulsive disorder', Psychiatric Clinics of North America, 2000, 23, (3), pp. 563586

[2] Tass, P.A.: 'A model of desynchronizing deep brain stimulation with a demand-controlled coordinated reset of neural subpopulations', Biological cybernetics, 2003, 89, (2), pp. 81-88

[3] Bucci, P., Mucci, A., Volpe, U., Merlotti, E., Galderisi, S., and Maj, M.: 'Executive hypercontrol in obsessive-compulsive disorder: electrophysiological and neuropsychological indices', Clinical neurophysiology, 2004, 115, (6), pp. 1340-1348

[4] Pogarell, O., Juckel, G., Mavrogiorgou, P., Mulert, C., Folkerts, M., Hauke, W., Zaudig, M., Möller, H.J., and Hegerl, U.: 'Symptom-specific EEG power correlations in patients with obsessivecompulsive disorder', International journal of psychophysiology, 2006, 62, (1), pp. 87-92

[5] Velikova, S., Locatelli, M., Insacco, C., Smeraldi, E., Comi, G., and Leocani, L.: 'Dysfunctional brain circuitry in obsessive-compulsive disorder: 
source and coherence analysis of EEG rhythms', Neuroimage, 2010, 49, (1), pp. 977-983

[6] Welter, M.-L., Burbaud, P., Fernandez-Vidal, S., Bardinet, E., Coste, J., Piallat, B., Borg, M., Besnard, S., Sauleau, P., and Devaux, B.: 'Basal ganglia dysfunction in OCD: subthalamic neuronal activity correlates with symptoms severity and predicts high-frequency stimulation efficacy', Translational psychiatry, 2011, 1, (5), pp. e5

[7] Tóth, B., File, B., Boha, R., Kardos, Z., Hidasi, Z., Gaál, Z.A., Csibri, É., Salacz, P., Stam, C.J., and Molnár, M.: 'EEG network connectivity changes in mild cognitive impairment-Preliminary results', International Journal of Psychophysiology, 2014, 92, (1), pp. 1-7

[8] Dauwels, J., Vialatte, F., Musha, T., and Cichocki, A.: 'A comparative study of synchrony measures for the early diagnosis of Alzheimer's disease based on EEG', NeuroImage, 2010, 49, (1), pp. 668-693

[9] Cui, D., Liu, X., Wan, Y., and Li, X.: 'Estimation of genuine and random synchronization in multivariate neural series', Neural Networks, 2010, 23, (6), pp. 698-704

[10] Lee, S.H., Park, Y.M., Kim, D.W., and Im, C.H.: 'Global synchronization index as a biological correlate of cognitive decline in Alzheimer's disease', Neurosci Res, 2010, 66, (4), pp. 333339

[11] Wen, D., Xue, Q., Lu, C., Guan, X., Wang, Y., and Li, $X$.: 'A global coupling index of multivariate neural series with application to the evaluation of mild cognitive impairment', Neural Networks, 2014, 56, pp. 1-9

[12] Koenig, T., Lehmann, D., Saito, N., Kuginuki, T., and Kinoshita, T.: 'Decreased functional connectivity of EEG theta-frequency activity in first-episode, neuroleptic-naive patients with schizophrenia:preliminary results', Schizophr Research, 2001, 50, pp. 55-60

[13] Koenig, T., Prichep, L., Dierks, T., Hubl, D., Wahlund, L.O., John, E.R., and Jelic, V.: 'Decreased EEG synchronization in Alzheimer's disease and mild cognitive impairment', Neurobiol Aging, 2005, 26, (2), pp. 165-171

[14] Purcell, R., Maruff, P., Kyrios, M., and Pantelis, C.: 'Cognitive deficits in obsessive-compulsive disorder on tests of frontal-striatal function', Biological psychiatry, 1998, 43, (5), pp. 348-357

[15] Aydin, S., Arica, N., Ergul, E., and Tan, O. 'Classification of obsessive compulsive disorder by EEG complexity and hemispheric dependency measurements', International journal of neural systems, 2015, 25, (03), pp. 1550010

[16] Ozcoban, M.A., Kara, S., Tan, O., and Aydin, S.: 'Investigation the level of neural synchronization by using global field synchronization method in Obsessive Compulsive Disorder', in Editor (Ed.)^(Eds.): 'Book Investigation the level of neural synchronization by using global field synchronization method in Obsessive Compulsive Disorder' (IEEE, 2014, edn.), pp. 1-3

[17] Association, A.P.: 'DSM 5' (American Psychiatric Association, 2013. 2013)

[18] Goodman, W.K., Price, L.H., Rasmussen, S.A., Mazure, C., Fleischmann, R.L., Hill, C.L., Heninger, G.R., and Charney, D.S.: 'The Yale-Brown obsessive compulsive scale: I. Development, use, and reliability', Archives of general psychiatry, 1989, 46, (11), pp. 1006-1011

[19] Williams, J.B.: 'A structured interview guide for the Hamilton Depression Rating Scale', Archives of general psychiatry, 1988,45 , (8), pp. 742-747

[20] Beck, A.T., Epstein, N., Brown, G., and Steer, R.A.: 'An inventory for measuring clinical anxiety: psychometric properties', Journal of consulting and clinical psychology, 1988, 56, (6), pp. 893

[21] Kubicki, S., Herrmann, W., Fichte, K., and Freund, G.: 'Reflections on the topics: EEG frequency bands and regulation of vigilance', Pharmakopsychiatrie, NeuroPsychopharmakologie, 1979, 12, (2), pp. $237-$ 245

[22] Knyazev, G.G., Savostyanov, A.N., Bocharov, A.V., and Rimareva, J.M.: 'Anxiety, depression, and oscillatory dynamics in a social interaction model', Brain research, 2016, 1644, pp. 62-69 